\title{
REDUKSI ARUS ASUT PADA START UP MOTOR INDUKSI SATU FASA MENGGUNAKAN AC-AC KONVERTER BERBASIS MIKROKONTROLER
}

\author{
Lewi ${ }^{1}$, Muh. Yusuf Yunus ${ }^{1}$, Paniman Palengai ${ }^{2}$, Zein Rahimul Iman ${ }^{2}$
}

\begin{abstract}
Abstrak: Motor induksi secara umum dapat distarting dengan menghubungkan motor secara langsung ke jalajala PLN. Dengan menghubungkan secara langsung dapat menarik arus yang tinggi sehingga mengakibatkan drop tegangan, serta dapat mempengaruhi peralatan listrik pada saluran yang sama. Penelitian ini bertujuan untuk membuat sebuah alat yang dapat mengurangi arus asut pada start up motor induksi, juga untuk mengetahui mengetahui prinsip kerja dari alat yang dibuat. Metode yang digunakan adalah metode komparasi. Yang dimaksud metode komparasi adalah metode yang dimaksudkan untuk mengetahui, membandingkan dan menguji perbedaan dua kelompok percobaan atau lebih. Pada pengujian motor tanpa menggunakan arus asut, diperoleh arus starting sebesar 2,4 A sedangkan pada pengujian menggunakan alat pereduksi arus asut, diperoleh arus startingnya sebesar 2,25 A. Dengan menggunakan alat preduksi arus asut pada start up motor induksi satu fasa yang telah dibuat, mampu mengatur sudut pemicuan TRIAC. Sehingga pada starting awal motor induksi satu fasa, arus dapat diatur kurang dari arus starting tanpa menggunakan alat.
\end{abstract}

Kata kunci : Motor induksi satu fasa, AC-AC konverter, dan Mikrokontroller

\section{PENDAHULUAN}

Pada era moderen sekarang ini, penggunaan motor listrik sangat banyak digunakan pada industri maupun rumah tangga. Motor listrik tersebut terbagi menjadi dua berdasarkan jumlah fasanya yaitu, satu fasa dan tiga fasa. Sedang untuk pemilihan jenis motornya disesuaikan dengan keperluan. Dari sekian banyak kegunaan yang dimiliki, contoh penggunaan pada industri salah satunya yaitu pada motor konveyor dalam hal ini motor konveyor skala kecil sedangkan contoh penggunaan pada rumah tangga yaitu pada mesin cuci, pompa air, kipas angin, AC, dan yang lainnya. Motor induksi adalah salah satu jenis motor listrik yang paling banyak digunakan pada industri dan rumah tangga. Motor ini kelebihannya seperti desain yang sederhana, murah, pemeliharaan rendah serta dapat disambung langsung ke sumber listrik. Motor ini dapat distarting dengan menghubungkan motor secara langsung ke sumber listrik. Namun kita ketahui jika motor listrik ketika distarting secara langsung akan menarik arus yang tinggi, secara teori bisa sampai 5 kali lebih besar dari arus nominal (parekh, 2003). Arus start ini dapat mengakibatkan drop tegangan, sehingga dapat mempengaruhi atau merusak peralatan listrik pada saluran yang sama. Salah satu metode pereduksian arus starting motor dengan menggunakan AC-AC konverter, di mana komponen utama dari AC-AC konverter ini yaitu TRIAC. Saat ini penggunaan alat-alat kontrol sangat banyak digunakan, salah satunya menggunakan mikrokontroller. Mikrokontroler adalah sebuah sistem mikroprosesor lengkap yang terkandung di dalam sebuah chip. Mikrokontroller sangat mudah di dapat dipasaran dengan harga yang terjangkau. Jadi untuk mengurangi arus asut motor induksi satu fasa dapat digunakan AC-AC konverter yang dikontrol oleh mikrokontroller.

\subsection{Motor induksi}

Motor induksi merupakan motor yang paling umum digunakan pada berbagai peralatan industri dan rumah tangga. hal ini disebabkan karena rancangannya yang sederhana, murah dan mudah didapat, dan dapat langsung disambungkan ke sumber daya AC. Motor induksi dapat diklasifikasikan menjadi dua kelompok utama (Parekh, 2003) yaitu : Motor induksi satu fase dan motor induksi tiga fase. Motor induksi satu fasa sering disebut dengan motor asinkron atau motor tak serempak, karena

\footnotetext{
${ }^{1}$ Staf Pengajar D4 Jurusan Teknik Mesin Politeknik Negeri Ujung Pandang

${ }^{2}$ Alumni Program D4 Jurusan Teknik Mesin Politeknik Negeri Ujung Pandang
} 
putaran medan stator tidak sama dengan putaran medan rotor. Putaran sikron stator (ns) selalu mendahului atau lebih cepat dari putaran medan rotor (nr). Jenis-jenis motor induksi satu fasa terbagai atas motor universal, motor repulsi, motor kapasitor (Motor kapasitor Start, Motor Kapasitor Permanen,dan Motor Kapasitor ganda (start/running)), dan motor fasa belah.

\subsection{AC-AC Converter}

Dalam ilmu elektronika daya atau Power Electronics dikenal beberapa jenis pengaturan untuk mengatur tegangan AC, salah satunya adalah dengan metode kontrol fasa. Cara kerja metode kontrol fasa yaitu meredam bagian dari gelombang sinusoidal setiap setengah periode atau satu periode penuh. Komponen yang dapat digunakan untuk metode ini adalah TRIAC atau sepasang thyristor yang dipasang secara berlawanan arah. Kondisi TRIAC terbuka atau tertutup tergantung pada penyulutan dari Gate Driver. TRIAC akan pada kondisi terbuka jika gate pada TRIAC tidak mendapatkan penyulutan, pada kondisi ini terdapat bagian dari gelombang sinus yang teredam sepanjang beberapa derajat. Jika gate pada TRIAC mendapatkan penyulutan, maka TRIAC pada kondisi tertutup, sehingga pada kondisi ini gelombang sinus dapat muncul namun tidak secara penuh.

\subsection{TRIAC}

TRIAC merupakan komponen semikonduktor yang tersusun atas dioda empat lapis berstruktur p-n-p-n dengan tipe p-n junction. TRIAC memiliki tiga buah elektroda, yaitu: gate, MT1, MT2. TRIAC adalah jenis thyristor yang uni-directional.

\subsection{IC TCA}

IC TCA 785 adalah IC yang memicu keluarnya gelombang yang digunakan sebagai penyulut agar dapat mengeluarkan gelombang sebagaimana mestinya agar dapat digunakan untuk menyulut. Rangkaian driver TCA berfungsi sebagai pembangkit pulsa dari rangkaian AC-AC Konverter satu fasa.

\subsection{Mikrokontroller}

Mikrokontroller adalah sebuah sistem mikroprosesor lengkap yang terkandung di dalam sebuah chip. Berdasarkan arsitekturnya, mikrokontroller sendiri cenderung dibedakan menjadi 2 yaitu tipe CISC dan RISC.

\subsection{Code Vision AVR}

Code Vision AVR merupakan suatu software yang digunakan dalam penulisan program yang nantinya akan di download pada microcontroller AVR ATMega16.

\subsection{Driver Relay}

Relay adalah komponen yang terdiri dari sebuah kumparan berinti besi yang akan menghasilkan elektromagnet ketika kumparan dialiri oleh arus listrik. Elekromagnet ini kemudian menarik mekanik kontak yang akan menghubungkan kontak Normally_open (NO) dan membuka kontak NormallyClosed (NC).

\subsection{DAC (Digital Analog Converter) dan OP-AMP (Operation Amplifier)}

Digital Analog Converter adalah suatu rangkaian elektronika yang berfungsi untuk merubah besaran digital menjadi besaran analog. Rangkaian ini diperlukan pada saat rangkaian memberikan output berupa sinyal digital kemudian dirubah menjadi sinyal analog. Operation Amplifier adalah suatu penguat berpenguatan tinggi yang terintegrasi dalam sebuah chip IC yang memiliki dua input inverting dan non-inverting dengan sebuah terminal output, dimana rangkaian umpan balik dapat ditambahkan untuk mengendalikan karakteristik tanggapan keseluruhan pada Operation Amplifier. 
91 Lewi, Muh. Yusuf Yunus, Paniman Palengai, Zein Rahimul Iman. Reduksi Arus Asut Pada Start Up Motor Induksi Satu Fasa Menggunakan Ac-Ac Konverter Berbasis Mikrokontroler

\subsection{Penyearah}

Penyearah adalah alat yang digunakan untuk mengubah sumber arus bolak-balik (AC) menjadi sumber arus searah (DC). Penyarah dibedakan menjadi 2 jenis yaitu penyearah setengah gelombang dan penyearah gelombang penuh. Penyearah gelombang penuh dibedakan menjadi penyearah gelombang penuh dengan center tapped (CT) dan penyearah gelombang penuh dengan mengunkan dioda bridge atau sistem jembatan.

\section{METODE PENELITIAN}

Lokasi perancangan dan penelitian alat pereduksi arus asut pada start up motor induksi satu fasa berbasis mikrokontroller bertempat di Laboratorium Energi Politeknik Negeri Ujung Pandang. Metode yang akan digunakan dalam proyek akhir ini adalah metode komparasi. Yang dimaksud dengan metode komparasi adalah metode yang dimaksudkan untuk mengetahui, membandingkan dan atau menguji perbedaan dua kelompok percobaan atau lebih. Dengan menggunakan metode ini maka dapat dibandingkan antara hasil pengujian yang menggunakan alat pereduksi arus asut dengan pengujian yang tidak menggunakan alat pereduksi arus asut. Kemudian hasil perbandingannya dapat dilihat dengan menggunakan grafik. Proses penelitian dapat dilihat pada flowchart dibawah ini.

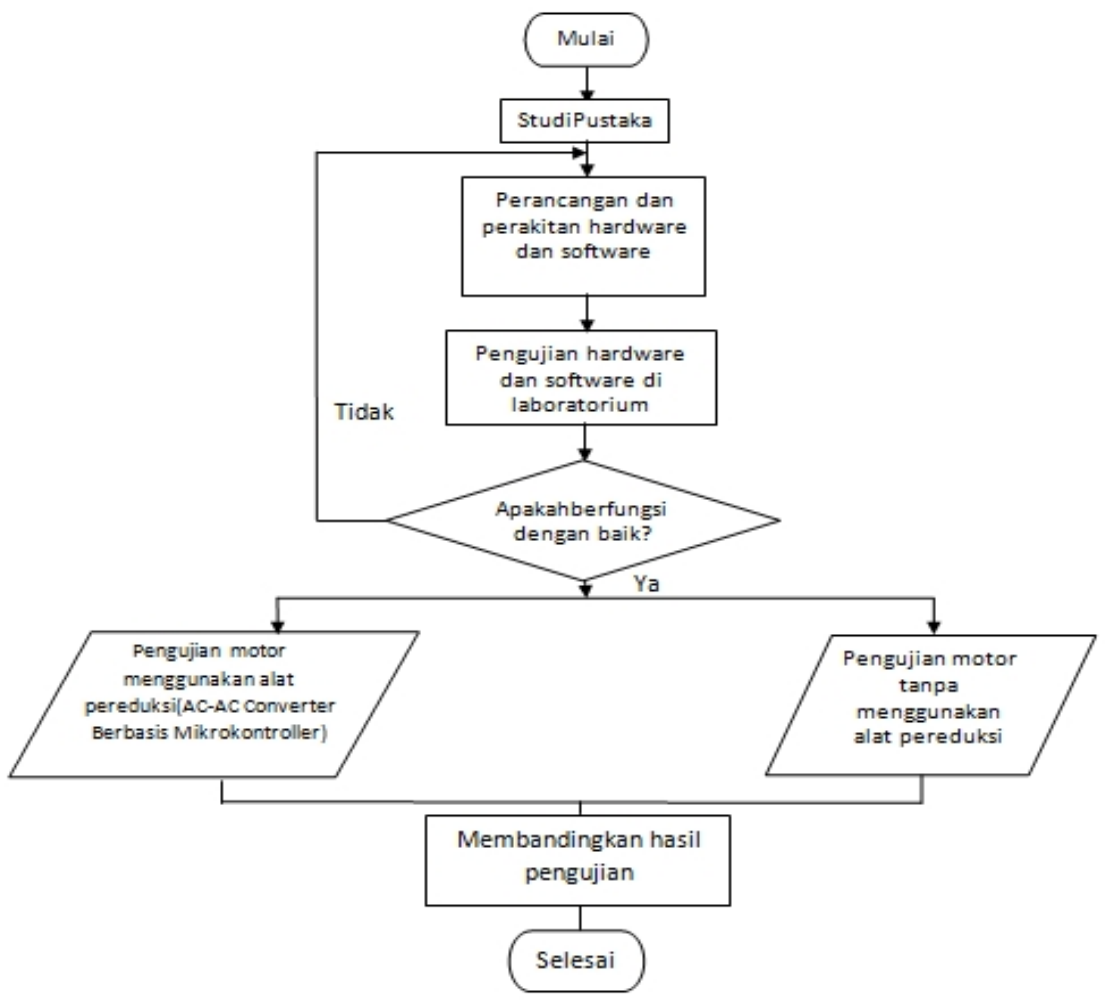

Gambar 1. Flowchart prosedur penelitian

Dalam pengujian ini kami akan membandingkan secara umum antara hasil yang dicapai jika menggunakan alat pereduksi arus asut yang kami buat (AC-AC Converter berbasis mikrokontroller) dengan hasil pengujian motor secara langsung tanpa menggunakan alat pereduksi. Perancangan alat pereduksi arus asut pada start up motor induksi satu fasa terbagi dalam 2 bagian yaitu, perancangan perangkatan keras berupa penentuan motor yang akan digunakan, penentuan TRIAC, penentuan sensor arus yang akan digunakan, perancangan rangkaian TCA, penentuan mikrokontroller, perancangan rangkaian DAC, perancangan rangkaian penyearah, perancangan driver relay. Bagian kedua adalah perancangan perangkat lunak berupa diagram alir alat pereduksi kemudian membuat programnya menggunakan software CodeVision AVR. Alat dan bahan yang digunakan pada pembuatan alat 
pereduksi arus asut terdiri dari : Mesin bor tangan, mesin gerinda tangan, solder, multimeter, tang potong, tang lancip, obeng (+ dan - ), TRIAC, IC TCA, dioda, resistor, tima, papan PCB, mikrokontroller, dan kabel

\section{HASIL DAN PEMBAHASAN}

\subsection{Hasil}

Hasil pengujian dilakukan dengan dua tahap yaitu pengujian parsial dan pengujian integrasi. Dalam pengujian parsial dilakukan beberapa pengujian alat meliputi.

\section{Pengujian rangkaian penyearah jembatan penuh satu fasa}

Pengujian rangkaian penyearah jembatan penuh satu fasa dilakukan dengan cara memberikan tegangan sumber dari jala-jala PLN 220 Volt, kemudian tegangan tersebut diturunkan menggunkan trafo step down menjadi 9 Volt, 12 Volt, dan 15 Volt. Pengujian output tegangan trafo step down dapat dilihat pada gambar 2 berikut:

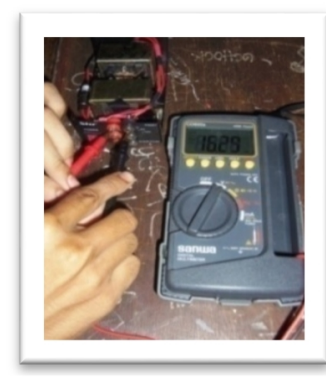

(a)

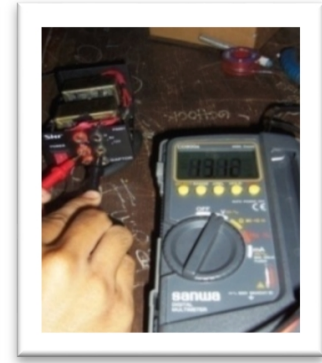

(b)

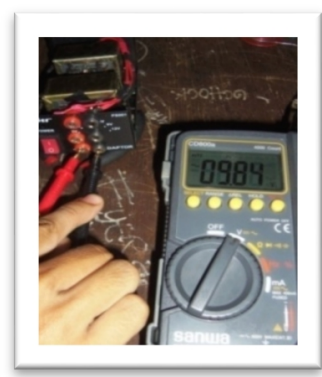

(c)

Gambar 2. Pengujian output tegangan trafo step down (a). tegangan 15 Vac,(b). tegangan 12 Vac, dan (c). tegangan 9 Vac

Dalam pengujian yang telah dilakukan, sebagai perbandingan antara tegangan output pengukuran penyearah dengan tegangan output teori penyearah. Tegangan output teori dapat dicari dengan menggunakan persamaan (3) dan hasil dari analisa data dapat diliahat pada tabel 1.

$\mathrm{Vdc}=\mathrm{Vm}-\frac{\mathrm{V}(\mathrm{p})}{2}=\mathrm{Vm}-\frac{\mathrm{V}}{4}$

Dan untuk mencari \% error tegangan keluaran dari penyearah dapat dicari dengan menggunakan persamaan (4) dan hasil analisa data dapat dilihat pada table 1 adalah :

$\%$ error $=\left|\frac{\mathrm{V} \mathrm{t}_{1}-\mathrm{V} \mathrm{p}_{\mathrm{i}}}{\mathrm{V} \mathrm{t}_{\mathrm{t}}}\right| \times 100 \%$

Tabel 1. Keluaran Penyearah jembatan satu fasa
\begin{tabular}{|c|c|c|c|c|}
\hline No & $\mathbf{V}_{\text {in }}$ & $\mathbf{V}_{\text {out }}$ pengujian & $\mathbf{V}_{\text {out }}$ teori & $\%$ error \\
\hline 1 & 9,84 & 11,89 & 13,92 & 14,56 \\
\hline 2 & 11,89 & 14,95 & 16.82 & 4.84 \\
\hline
\end{tabular}

\section{Pengujian rangkaian DAC dan Op-Amp}

Dalam pengujian DAC tanpa Op-Amp yang telah dilakukan, sebagai perbandingan antara tegangan output pengukuran dengan tegangan output teori, dapat di cari dengan menggunakan persamaan (5) dan untuk mencari \% error tegangan keluaran DAC tanpa Op-Amp dapat menggunakan persamaan (4) dan hasil analisa data dapat dilihat pada table 2.

$$
\mathrm{V}_{\mathrm{o}} \text { teori } \quad=\mathrm{V}_{\text {ref }} \mathrm{x}\left(\frac{n d}{2^{n}}\right) \ldots \ldots \ldots \ldots \text { (5) }
$$

Sedangkan dalam pengujian DAC dengan menggunakan Op-Amp yang telah dilakukan sebagai perbandingan antara tegangan output pengukuran dengan tegangan output teori, dapat menggunakan persamaan (6) dan untuk mencari \% error tegangan keluaran DAC dengan menggunakan Op-Amp dapat menggunakan persamaan (4) dan hasil analisa data dapat dilihat pada table 3.

$$
\mathrm{V}_{\mathrm{o}} \quad=\mathrm{V}_{\text {in }} \mathrm{x}\left(1+\frac{R 1}{R}\right)
$$


93 Lewi, Muh. Yusuf Yunus, Paniman Palengai, Zein Rahimul Iman. Reduksi Arus Asut Pada Start Up Motor Induksi Satu Fasa Menggunakan Ac-Ac Konverter Berbasis Mikrokontroler

Tabel 2. Pengujian dan analisa data DAC R/2R tanpa Op-Amp

\begin{tabular}{|c|c|c|c|c|}
\hline No & Desimal & $\mathrm{V}_{\text {out }}$ Pengujian (Volt) & $\mathrm{V}_{\text {out }}$ teori (Volt) & \%error \\
\hline 1 & 15 & 0,37 & 0,29 & $-26,28$ \\
\hline 2 & 30 & 0,78 & 0,59 & $-33,12$ \\
\hline 3 & 45 & 1,03 & 0,88 & $-17,19$ \\
\hline 4 & 60 & 1,53 & 1,17 & $-30,56$ \\
\hline 5 & 75 & 1,62 & 2,05 & $-10,59$ \\
\hline 6 & 90 & 1,89 & 2,34 & $-7,52$ \\
\hline 7 & 105 & 2,14 & 2,64 & $-4,35$ \\
\hline 8 & 120 & 2,48 & 2.34 & $-5,81$ \\
\hline 9 & 135 & 2,99 & 2,64 & $-13,39$ \\
\hline 10 & 150 & 3,15 & 2,93 & $-7,52$ \\
\hline 11 & 165 & 3,56 & 3,23 & $-10,48$ \\
\hline 12 & 180 & 3,58 & 3,51 & $-1,83$ \\
\hline 13 & 195 & 4,15 & 3,81 & $-8,96$ \\
\hline 14 & 210 & 4,40 & 4,10 & $-7,27$ \\
\hline 15 & 225 & 4,42 & 4,39 & $-0,58$ \\
\hline 16 & 240 & 4,71 & 4,69 & $-0,48$ \\
\hline 17 & 255 & 4,97 & 4,98 & 0,21 \\
\hline
\end{tabular}

Tabel 3. Pengujian dan analisa data DAC R/2R dengan Op-Amp

Tabel 3. Pengujian dan analisa data DAC R/2R dengan Op-Amp
\begin{tabular}{|c|c|c|c|c|}
\hline No & Desimal & $\begin{array}{c}\mathrm{V}_{\text {out }} \text { Pengujian } \\
\text { (Volt) }\end{array}$ & $\mathrm{V}_{\text {out }}$ teori (Volt) & \%error \\
\hline 1 & 15 & 0,77 & 0,59 & $-31,41$ \\
\hline 2 & 30 & 1,49 & 1,17 & $-27,15$ \\
\hline 3 & 45 & 1,93 & 1,76 & $-9,80$ \\
\hline 4 & 60 & 2,47 & 2,34 & $-5,39$ \\
\hline 5 & 75 & 3,11 & 2,93 & $-6,15$ \\
\hline 6 & 90 & 3,66 & 3,52 & $-4,11$ \\
\hline 7 & 105 & 4,17 & 4,10 & $-1,67$ \\
\hline 8 & 120 & 5,21 & 4,69 & $-11,15$ \\
\hline 9 & 135 & 5,35 & 5,27 & $-1,45$ \\
\hline 10 & 150 & 5,76 & 5,86 & 1,70 \\
\hline 11 & 165 & 6,47 & 6,45 & $-0,38$ \\
\hline 12 & 180 & 6,80 & 7,03 & 3,29 \\
\hline 13 & 195 & 7,38 & 7,62 & 3,11 \\
\hline 14 & 210 & 7,94 & 8,20 & 3,21 \\
\hline 15 & 225 & 8,42 & 9,79 & 4,20 \\
\hline 16 & 240 & 8,85 & 9,38 & 5,60 \\
\hline 17 & 255 & 9,05 & 9,96 & 9,15 \\
\hline
\end{tabular}

\section{Pengujian rangkaian $\mathrm{AC}-\mathrm{AC}$ Konverter}

Pengujian rangkaian AC-AC konverter dilakukan dengan menggunakan beban lampu pijar 100 watt dengan input tegangan sebesar 220 Volt. Pengujian rangkaian AC-AC konverter dilakukan dengan memberi sinyal desimal 255 sampai 0 dengan pengurangan 15 step. Hasil pengujian dapat dilihat pada tabel 4 berikut.

Tabel 4. Hasil pengujian rangkaian AC-AC konverter

\begin{tabular}{|c|c|c|c|c|c|}
\hline No. & $\begin{array}{c}\text { Tegangan } \\
\text { kontrol (Volt) }\end{array}$ & Desimal & $\begin{array}{c}\text { Sudut } \\
\text { penyulutan }\end{array}$ & \multirow{2}{*}{$\begin{array}{c}\text { Vin } \\
\text { (Volt) }\end{array}$} & $\begin{array}{c}\text { Vout } \\
\text { pengujian } \\
\text { (Volt) }\end{array}$ \\
\hline 1 & 9,05 & 255 & 13,86 & & 149,9 \\
\hline 2 & 8,85 & 240 & 26,82 & & 150,3 \\
\hline 3 & 8,42 & 225 & 34,74 & \multirow{2}{*}{235} & 151,1 \\
\hline 4 & 7,94 & 210 & 44,46 & & 154,8 \\
\hline 5 & 7,38 & 195 & 55,98 & & 159,6 \\
\hline
\end{tabular}




\begin{tabular}{|c|c|c|c|c|}
\hline 6 & 6,80 & 180 & 65,88 & 163,8 \\
\hline 7 & 6,47 & 165 & 75,06 & 169.6 \\
\hline 8 & 5,76 & 150 & 93,78 & 175,5 \\
\hline 9 & 5,35 & 135 & 96,3 & 182,6 \\
\hline 10 & 5,21 & 120 & 103,68 & 188,7 \\
\hline 11 & 4,17 & 105 & 116,46 & 195,5 \\
\hline 12 & 3,66 & 90 & 122,4 & 202,9 \\
\hline 13 & 3,11 & 75 & 132,84 & 210,3 \\
\hline 14 & 2,47 & 60 & 142,92 & 218,2 \\
\hline 15 & 1,93 & 45 & 151,56 & 221,7 \\
\hline 16 & 1,49 & 30 & 159,3 & 226,4 \\
\hline 17 & 0,77 & 15 & 162,9 & 230,5 \\
\hline
\end{tabular}

\section{Pengujian Rangkaian Driver Relay}

Pengujian rangkaian relay dilakukan dengan menset pada mikrokontroller. Relay akan bekerja ketika kontrol dinyalakan untuk menyambungkan sumber tegangan ke motor induksi melalui rangkaian AC-AC konverter dan bekerja kembali ketika keluaran DAC sudah mencapai nilai desimal 15 untuk menyambungkan sumber tegangan ke motor induksi tanpa melewati rangkaian AC-AC konverter. Sedangkan untuk pengujian integrasi dilakukan pengujian secara menyeluruh alat reduksi arus asut pada start up motor induksi satu fasa.

\section{Pengujian tanpa menggunakan alat pereduksi arus asut pada start up motor (DOL).}

Pengujian motor tanpa menggunakan alat pereduksi arus asut dilakukan dengan cara menyambungkan langsung motor induksi ke jala-jala PLN. Data hasil pengujian dapat dilihat pada table 5 berikut ini.

Tabel 5. Hasil Pengujian tanpa menggunkanan alat pereduksi (DOL)

\begin{tabular}{|c|c|c|c|}
\hline No & Vin & Arus starting (A) & Arus Steady (A) \\
\hline 1 & 232 & 2,4 & 1,6 \\
\hline
\end{tabular}

\section{Pengujian menggunakan alat pereduksi arus asut pada start up motor.}

Data pengujian menggunakan alat pereduksi arus asut pada start up motor dapat dilihat pada tabel 6 berikut.

Tabel 6. Hasil Pengujian menggunkanan alat pereduksi arus asut pada start up

\begin{tabular}{|c|c|c|c|c|}
\hline No & Desimal & $\mathrm{V}_{\text {out }}$ DAC & $\begin{array}{c}\mathrm{V}_{\text {out }} \text { AC-AC } \\
\text { Konverter }\end{array}$ & Arus \\
\hline 1 & 255 & 0,77 & 174,8 & 1,4 \\
\hline 2 & 240 & 1,49 & 180,7 & 1,4 \\
\hline 3 & 225 & 1,93 & 182,8 & 1,4 \\
\hline 4 & 210 & 2,47 & 162,7 & 1,5 \\
\hline 5 & 195 & 3,11 & 176,7 & 1,65 \\
\hline 6 & 180 & 3,66 & 185,2 & 1,7 \\
\hline 7 & 165 & 4,17 & 190,5 & 1,75 \\
\hline 8 & 150 & 5,21 & 193,3 & 1,9 \\
\hline 9 & 135 & 5,35 & 197,7 & 2 \\
\hline 10 & 120 & 5,76 & 153,7 & 1,5 \\
\hline 11 & 105 & 6,47 & 162,8 & 1,55 \\
\hline 12 & 90 & 6,80 & 185,2 & 1,7 \\
\hline 13 & 75 & 7,38 & 192,9 & 1,9 \\
\hline 14 & 60 & 7,94 & 195,7 & 2,1 \\
\hline 15 & 45 & 8,42 & 202,2 & 2,25 \\
\hline 16 & 30 & 8,85 & 202,6 & 2,25 \\
\hline 17 & 15 & 9,05 & 203,1 & 2,3 \\
\hline 18 & 0 & 0 & 0 & 0 \\
\hline 19 & Bypass/Relay & & 233,3 & 1,65 \\
\hline & $\mathrm{I}_{\text {start }}=2,25$ & & & $\mathrm{~T}_{\text {Steady }}=1,65$ \\
\hline
\end{tabular}


95 Lewi, Muh. Yusuf Yunus, Paniman Palengai, Zein Rahimul Iman. Reduksi Arus Asut Pada Start Up Motor Induksi Satu Fasa Menggunakan Ac-Ac Konverter Berbasis Mikrokontroler

\subsection{Pembahasan}

Salah satu cara mengurangi arus asut pada start up motor induksi satu fasa dengan cara mengontrol sudut fasa dengan menggunakan AC-AC konverter. Dengan menggunakan AC-AC konverter arus start motor dapat diredam sebesar 0,15 A dari arus starting motor tanpa menggunakan alat pereduksi arus asut.

1. Grafik hubungan antara arus (A) dan waktu (s)

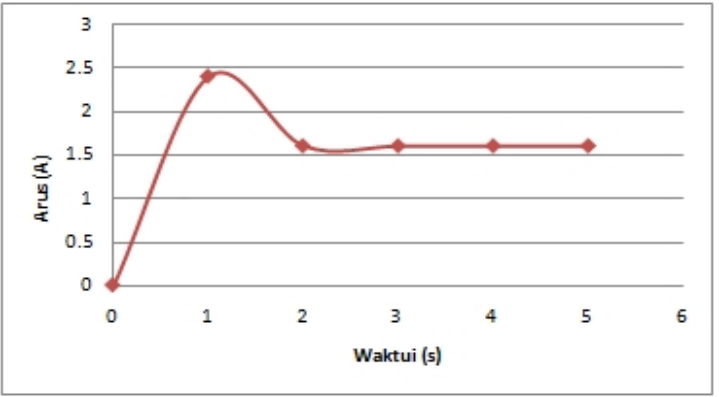

Gambar 3. Grafik hubungan antara waktu pengujian dengan arus starting pada pengujian motor induksi tanpa menggunakan alat pereduksi arus asut (DOL)

Pada Gambar 3 untuk pengujian motor induksi tanpa menggunakan alat peruduksi (DOL), diperoleh hasil pengujian yang dapat dilihat bahwa arus starting motor induksi sebesar 2,4 A. Dan memiliki arus steady sebesar 1,6 A.

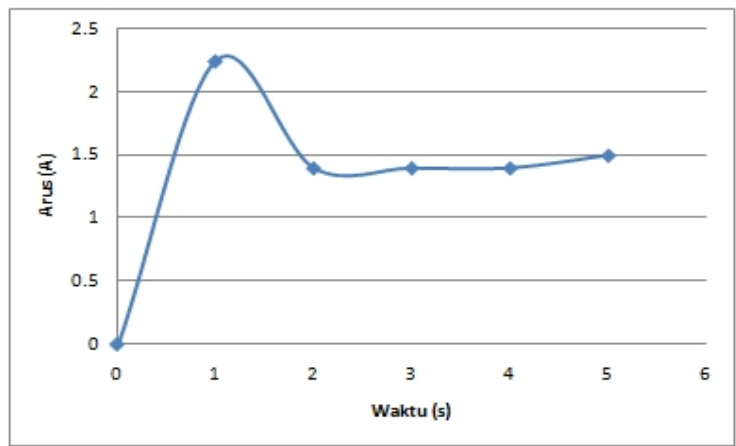

Gambar 4. Grafik hubungan antara waktu pengujian dengan arus starting pada pengujian motor induksi menggunakan alat pereduksi arus asut

Pada Gambar 4 untuk pengujian motor induksi satu fasa menggunakan alat pereduksi arus asut, diperoleh arus starting awal 2,25 A kemudian arus turun pada detik 2 dengan arus 1,4 A. Kemudian arus naik secara perlahan-lahan.

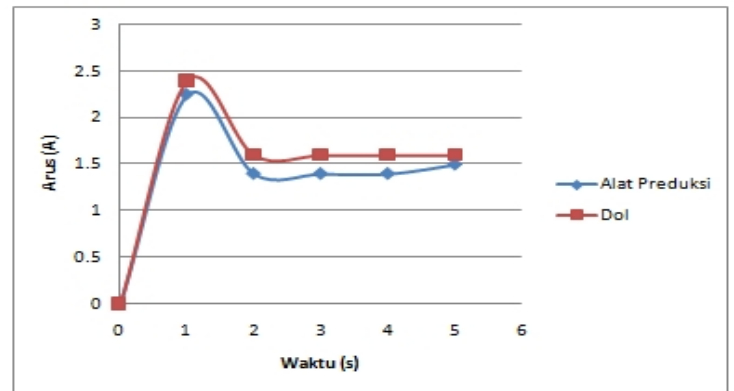

Gambar 5. Grafik hubungan antara waktu pengujian dengan arus starting pada pengujian motor induksi tidak (DOL) dan menggunakan alat pereduksi arus asut 
Pada gambar 5 dapat dilihat bahwa dengan menggunakan alat pereduksi arus asut, arus startingnya lebih kecil dibandingkan dengan arus starting tanpa menggunkana alat (Metode DOL). Arus starting tanpa menggunakan alat peruduksi arus asut (Metode DOL) sebesar 2,4 A dengan arus steady 1,6 sedangkan dengan menggunakan alat pereduksi arus asut sebesar 2,25 A dengaan arus steady $1,5 \mathrm{~A}$.

\section{KESIMPULAN}

1. Dengan menggunakan alat preduksi arus asut pada start up motor induksi satu fasa yang telah dibuat mampu mengatur sudut pemicuan TRIAC sehingga pada starting awal motor induksi satu fasa, arus dapat diatur kurang dari arus starting tanpa menggunakan alat (DOL).

2. Besarnya arus starting awal mengunakan alat pereduksi sebesar 2,25 A, sedangkan tanpa alat perduksi arus strating awalnya 2,4 Amper.

3. Pada perancangan AC-AC konverter TRIAC yang digunakan berkapasitas $10 \mathrm{~A}$.

\section{DAFTAR PUSTAKA}

Anonim. 2008., Motor Listrik. http://dunia-listrik.blogspot.com/2008/12/motor-listrik.html. Diakses Pada Tanggal 6 februari 2014.

Anonim. 2008., Pengantar Mikrokontroller. http://polong.wordpress.com/2008/03/19/pengantarmikrokontroler/. Diakses pada tanggal 7 Februari 2014.

Anonim. 2011., Jenis-jenis mikrokontroller. http://inbroshare.blogspot.com/2011/10/jenis-jenismikrokontroler.html. Diakses pada tanggal 10 Februari 2014.

Anonim. 2011., Motor Listrik AC 1 Fasahttp://www.electronicglobal.com/2011/09/motor-listrik-ac1-fasa.html. Diakses pada tangal 11 Februari 2014.

Anonim. 2013., Fungsi IC TCA 785. http://diditnote.blogspot.com/2013/02/ic-tca-785.html. Diakses pada tanggal 11 Februari 2014.

Anonim. 2013., Motor Listrik. id.wikipedia.org/wiki/Motor_listrik. Diakses pada tanggal 11 Februari 2014.

Fewson, Denis.1998.Introduction To Power Electronic. Arnold.

Hidayat, Rahmat. 2013., Pengaturan Kecepatan Putaran Motor Induksi 1 Phasa Berbasis

Mikrokontroler ATMEGA8535, Dalam Jurnal Elektronik Universitas Pakuan Bogor [Online], 10 halaman. Tersedia: http://ejournal.unpak.ac.id/download.php?file=mahasiswa\&id=701\&name=RAHMAT+HIDAYA $\mathrm{T}+(054108011)+(\mathrm{OK})$.pdf . Diakses Pada Tanggal 7 Februari 2014.

Korniawan, Andri. 2011. Rancang Bangun Rotary Dryer Sebagai Pengering Padi Berbasis Mikrokontroller. Jurusan Teknik Elektro Industri Politeknik Elektronika Negeri Surabaya Institut Teknologi Sepuluh Nopember Surabaya.

Parekh, Rakesh. 2003. AC Induction Motor Fundamentals. USA: Microchip Tech. Inc.

Primatama, A., dkk. 2013. Perancangan Soft Starter Motor Induksi Satu Fasa Dengan Metode Close Loop Menggunakan Mikrokontroller Arduino. dalam jurnal elektronik Universitas $\begin{array}{llll}\text { Brawijaya } & \text { [Online], halaman. }\end{array}$ http://elektro.studentjournal.ub.ac.id/index.php/teub/article/download/64/34. Diakses pada tanggal 19 Maret 2014

S Permana, Putra. 2013., Rangkaian TCA 785. http://itismine28.blogspot.com/2013/10/rangkaiantca-785.html. Diakses pada tanggal 11 Februari 2014. 